\title{
Effect of liquid smoke on surface morphology and tensile strength of Sago Fiber
}

\author{
Mukhlis Muslimin ${ }^{1,2}$, Kusno Kamil ${ }^{3}$, Sofyan Arif Setya Budi ${ }^{2}$ and I. N. G. Wardana \\ ${ }^{1}$ Department of Mechanical Engineering, Faculty of Engineering, \\ Khairun University, Ternate, Indonesia \\ ${ }^{2}$ Department of Mechanical Engineering, Faculty of Engineering, \\ Brawijaya University, Malang, Indonesia \\ Email: mukhlis@unkhair.ac.id \\ ${ }^{3}$ Department of Mechanical Engineering, Faculty of Engineering, \\ Universitas Muslim Indonesia, Makassar, Indonesia
}

\begin{abstract}
This study aims to identify the effect of liquid smoke treatment on surface morphology and tensile strength of sago fiber (SF), including chemical reactions during the treatment. The proposed study is divided into two steps, fiber treatment and property tests. The first treatment, SF was immersion in the liquid smoke solution for 1, 2, 3, 4, and 5 hours, then dried for 1 hour which then characterized SEM, universal machine testing machine, X-Ray diffractometer (XRD), and Fourier transform infrared spectrometer (FTIR). The acetic acid in liquid smoke reacts with fiber to form fiber-liquid and $\mathrm{H} 2 \mathrm{O}$ compounds. The heating process degrades $\mathrm{H} 2 \mathrm{O}$ content in fibers and decomposes $\mathrm{C}$ and $\mathrm{C}$ elements to close together forming strong chemical bonds so that the fiber morphology become rough, porous, grooved and increasing the tensile strength of the fiber. But excessive heating treatment makes fibers more fragile because the $\mathrm{H} 2 \mathrm{O}$ elements degrade too low. Dominant percentage of SF crystallization occurred after 4 and 5 hours, 64.7 and $66.9 \%$, respectively among other durations, a significant increase of tensile strength $50.813 \mathrm{MPa}$ was achieved by 1-hour immersion in liquid smoke. Hence, as alternative to improve the mechanical characteristics of SF, immersion in liquid smoke should be applied. Furthermore, studies of similar treatment on other natural fibers can also be considered in the future.
\end{abstract}

Keywords: Liquid smoke; surface morphology; tensile strength; Sago Fiber.

\section{INTRODUCTION}

In recent years, natural fibers have been widely studied by experts as industrial materials such as mengkuang fibers, palm fibers, akaa (corypha) fibers, king pineapple leaf fibers, coconut fibers, carica papaya fibers, albizia amara fibers, and juncus effuses L fibers [1-9]. This study discusses the treatment of Sago fiber (SF) using acetic acid in liquid smoke from coconut shell which is more eco-friendly than other alkali treatment. SF is one bio material that has its own uniqueness and also interesting because this material is obtained from midrib of sago trees which is widely found in tropical nations. Since hundreds of years ago, SF has been used as raw material for rope in Luwu regency of South Sulawesi and some other parts 
of eastern Indonesia. From the best of authors' knowledge, yet no report of SF utilization as engineering material. As its vast and potential source, utilization of SF may not be limited only as traditional ropes but also as composite reinforcing material. SF is relatively cheap, biodegradable, renewable resources, easy handling, and above all, it is environmental friendly.

The chemical composition of SF depends on few unavoidable factors, such as weathers, soil, plant origin, etc. [10,11]. However, it constantly consists of the main component of lignocelluloses (cellulose, hemicelluloses, and lignin). The basic unit of lignocelluloses macromolecules is hydroxyl group (-OH). This hydroxyl forms an intramolecular hydrogen bond and an inter-molecular and a hydrogen bond with a hydroxyl group of moisture. The major disadvantages of SF as composite materials are its hydrophilic characteristics and water contents, which reduce durability. Modification of SF surfaces to reduce its hydrophilic is possibly improving adhesion properties and increase the hydrophobic part of the fiber surface. These modifications can make it possible to change the orientation of the fiber into an alternative composite amplifier in the future.

Previous studies attempted various treatments on natural fibers including immersion in solutions $\left(\mathrm{NaOH}, \mathrm{KMnO}_{4}, \mathrm{H}_{2} \mathrm{O}_{2}\right.$, and seawater), heating with turmeric solution, and steaming $[2,3,6,10-13]$. The treatments had altered physical properties of fibers, such as lignin level reduction from coconut husk by immersion in $\mathrm{NaOH}$, cleared and shaped grooves by immersion in $\mathrm{KMnO}_{4}$ and $\mathrm{H}_{2} \mathrm{O}_{2}$ [3]. Treatment with $\mathrm{NaOH}$ removed hemicelluloses and lignin in natural fibers and decreased the moisture content [11]. Seawater immersion of straw fibers also degrades lignin layer while providing harder surfaces [5,12,14]. Heating treatment of akaa (corypha) midrib fiber with turmeric solution increased the level of cellulose compound and reduced lignin content, increasing fiber's strength [6]. Steaming of king pineapple leaves had a very significant effect on fiber surface morphology to became harder and grooved surfaces [15]. After fumigation, surface morphology of King pineapple leaf fibers (KPLF) was rough and grooved, fiber density increased, and the single fiber tensile strength was notably increased at the base of the leaf [4]. Chemical treatments are considered in modifying fiber surface properties [16]. When natural fibers soaked in alkali ( $\mathrm{NaOH} 5 \%$ ), most of the wax and other non-cellulosic substances on the surface were removed, create a cleaner, rough, and porous surfaces due to the peeled outer layer as the chemical components of fiber were found dissolved in alkali [17].

FTIR and XRD tests had complement some previous studies on natural fiber treatments. For example, akaa (corypha) midrid with turmeric solution treatment greatly affect the ability of $\mathrm{C}=\mathrm{C}$ and $\mathrm{O}=\mathrm{H}$ absorption[6], the lignin and hemicelluloses content in the KPLF (King pineapple leaf fibers) were reduced after fumigation [4]. In an XRD test of sugar palm fiber, a consistent emergence phenomenon of crystal peak diffraction occurred as reaction to seawater [5]. Chemical treatment leads to crystallization on the surface of the fiber, where alkali treatment improves the crystallinity and exhibits new chemical bond formation in the sponge-gourd fiber (SGF) [18].

From various treatments of natural fibers so far, just a few are considered as environmental friendly. Environmental friendly material such as liquid smoke is a unique material and potentially used for fiber treatment. Liquid smoke is product of pyrolysis process of natural substances from coconut shell supplies, reasonably cheap, and degraded naturally. It has similar content to other natural fibers consist of lignin, hemicelluloses, and cellulose. Liquid smoke has also potential uses as an all-natural antimicrobial $[19,20]$. In 
current applications, liquid smoke is utilized as natural preservatives due to its content of phenol and acid compounds, functioned as antibacterial, and antioxidant [21]. The main products of wood pyrolysis are phenols, carbonyls, and organic acids which are responsible for the flavor, color, and antimicrobial properties of liquid smoke [20]. The compounds of liquid smoke have hydrophilic properties due to their $\mathrm{OH}$ group molecules, classified into the polar compound with negative electrons; therefore easily bind to fiber lignin to form another compound.

Through extensive experiments of this study, mechanical characteristics of SF can be analyzed to reveal its potential as natural fiber for green composite applications. Alterations of tensile strength of SF specimen will be clarified by chemical reactions of C-O-H elements during immersion in liquid smoke. It is expected to have clear understanding on the correlation of liquid smoke treatment and the alteration of tensile strength of SF, including its potential as green fiber alternative.

\section{Materials}

\section{METHODS AND MATERIALS}

The raw materials of this research are Sago Fiber (SF) from Luwu regency, South Sulawesi province, Indonesia and liquid smoke made of coconut shells.

Table 1. Chemical components of liquid smoke.

\begin{tabular}{clc}
\hline No & Component & Percentage \\
\hline 1 & L-Alanine, ethyl ester, & 33.37 \\
& $\begin{array}{l}\text { 2-propanamine, 1-methoxy } \\
\text { 2-Pentanamine }\end{array}$ & \\
\hline 2 & Acetic acid, methyl ester & 07.39 \\
\hline 3 & 2,3-Butanedione, Acetic acid ethyl ester & 02.60 \\
\hline 4 & Acetic acid & 56.65 \\
\hline
\end{tabular}

\section{Liquid smoke treatments}

SF were separated from midrib leaf and cambium; then be immersed in the liquid smoke solution for certain durations, as shown in Table 2.

Table 2. Study notation.

\begin{tabular}{clll}
\hline No & Treatment & Notation & Remarks \\
\hline 1 & No Treatment & TP & No immersion, no drying \\
2 & 1 hour immersion & P1J & \\
3 & 2 hours immersion & P2J & \\
4 & 3 hours immersion & P3J & All dried at $43^{0} \mathrm{C}$ for 1 hour \\
5 & 4 hours immersion & P4J & \\
6 & 5 hours immersion & P5J & \\
\hline
\end{tabular}


Groups of the specimen were treated and coded as listed in Table 1. After being immersed, fibers were dried in an oven at temperature $43^{\circ} \mathrm{C}$ for one hour and then took out for slow cooling at room temperature.

\section{Morphology of SF}

The morphology of fiber surface of each group then is observed using electron microscope Vega 3 Tescan Scanning Electron Microscope (SEM) at the $5 \mathrm{kV}$ voltage.

\section{X-Ray Diffraction (XRD) of SF}

Rigaku Miniflex 11 was used to get X-Ray diffraction pattern (XRD). In this machine, a highvoltage supply $(30 \mathrm{kV}, 15 \mathrm{~mA})$ is used to produce $\mathrm{X}$-ray radiation. The specimens were stepwise scanned by the XRD over the operational range of scattering angle $(2 \theta)$ between $10^{0}$ and $60^{\circ}$ by steps of $0.02^{\circ}$. Percentage crystallinity $(\% \mathrm{Cr})$ was calculated as follow:

$$
\% \mathrm{Cr}=\frac{I_{10}}{I_{10}+I_{60}} \times 100
$$

$\mathrm{I}_{10}$ and $\mathrm{I}_{60}$ are the crystallines amorphous intensities at $2 \theta$ scale close to $10^{0}$ to $60^{\circ}$, respectively.

\section{Fourier Transforms Infrared Spectroscopy of SF}

Fourier Transform Infrared (FTIR) spectra of the samples were recorded at room temperature using Shimadzu prestige-21 model $8400 \mathrm{~S}$ in the wave number range of $250-4000 \mathrm{~cm}^{-1}$. For these measurements, the samples were crushed for recording the FTIR spectra in the transmittance $(\%)$ mode.

\section{Tensile Testing of SF}

Preparation of SF specimen is started by separation of fibers off the midrib leaf and cambium then grouped in of type of treatments, coded (Table 2) and isolated as single fibers based on ASTM D3379-75 standard. Codes of treatments (TP, P1J, P2J, P3J, P4J, and P5J) were labeled to each group of the 5 treatments. Total 25 specimens then underwent the tensile strength $(\sigma)$ tests by Universal Material Testing Machine type LR10K.

\section{RESULTS AND DISCUSSION}

\section{Morphology Observation}

Figure 1 shows surface morphology of SF. Figure 1(a) is the untreated fiber surface, while Figure1(b) to (f) indicate surfaces of SF with liquid smoke treatments, resulted in grooves, porous, and increased rough of the fiber surface. 

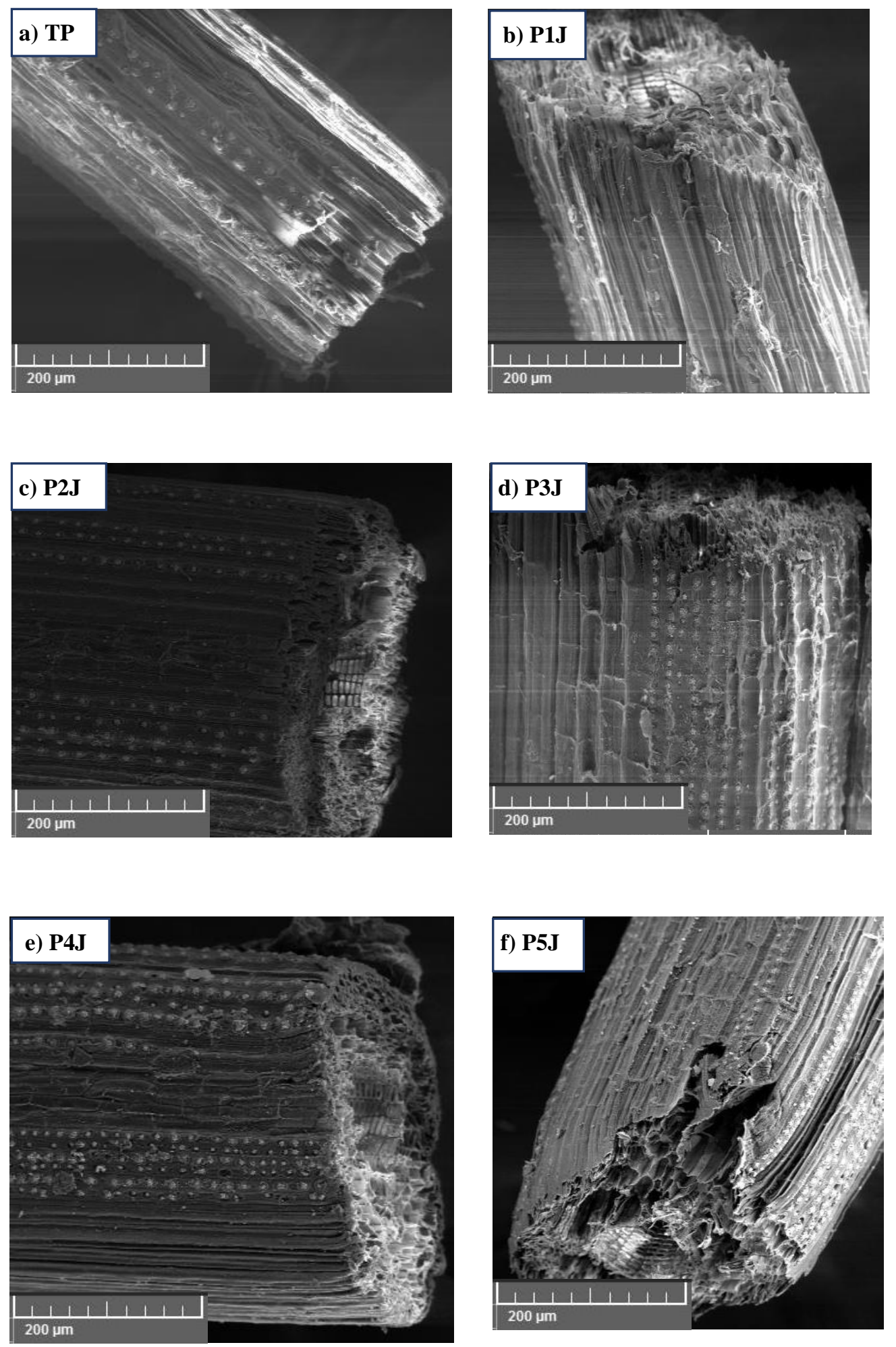

Figure 1. Surface morphologies of specimen with: (a) no treatment, (b) 1 hour immersion, (c) 2 hours immersion, (d) 3 hours immersion, (e) 4 hours immersion, and (f) 5 hours immersion. 
Figure 1(a) shows the surface of SF with no treatment is fairly smooth. This indicates that SF surface with lignin content is still abundant aligning on fibers surface. The figure shows the regular rectangular pattern and which is smooth on the surface of the fiber. However, after being treated with liquid smoke for 1, 2, 3, 4, and 5 hours, as shown in Figures. 1(b-f), respectively, the rectangular patterns of the surfaces are gradually rougher compared to the untreated one. The roughness depends on the duration of the liquid smoke treatments.

Figure 1(b) of 1 hour treatment shows a new pattern on the surface of SF. The surface starts to change into groove. After 2 hours immersion, the rectangular groove patterns become more arranged, visibly rough, and porous as shown in Figure 1(c). The morphology of the fiber surface with 3 hours of immersion indicates a rectangular, rough, and pore groove patterns and increased as shown in Figure 1(d).

Figure 1(e-f) show rougher patterns and clearer pores during the 4 and 5 hours treatments. In these cases, the plot is clearer, coarser and the pores clearer. Larger grooves, rough and pore patterns are expected to interact with fiber matrix compounds to increase the bond between fiber and matrix.

Figure 1(b-f) denotes a rough surface because the $\mathrm{OH}$ group content of the fiber has been degraded, and the surface becomes coarse, grooved, and porous by the effects of liquid smoke. The treatment of liquid smoke makes the surface roughness are distinguished from the fiber surface without treatment. The increased coarseness resulted from growing lignin on fibers surface, enriched by the composition of $\mathrm{H}$ and $\mathrm{O}$ elements in lignin compound along with the density of $\mathrm{C}$ bonds on the fibers, which also found in other studies [8].

\section{Crystalline Structure Observation}

In the XRD test results, visible differences between SF curve of TP andP1J, P2J, P3J, P4J, and P5J as shown in Figure 2

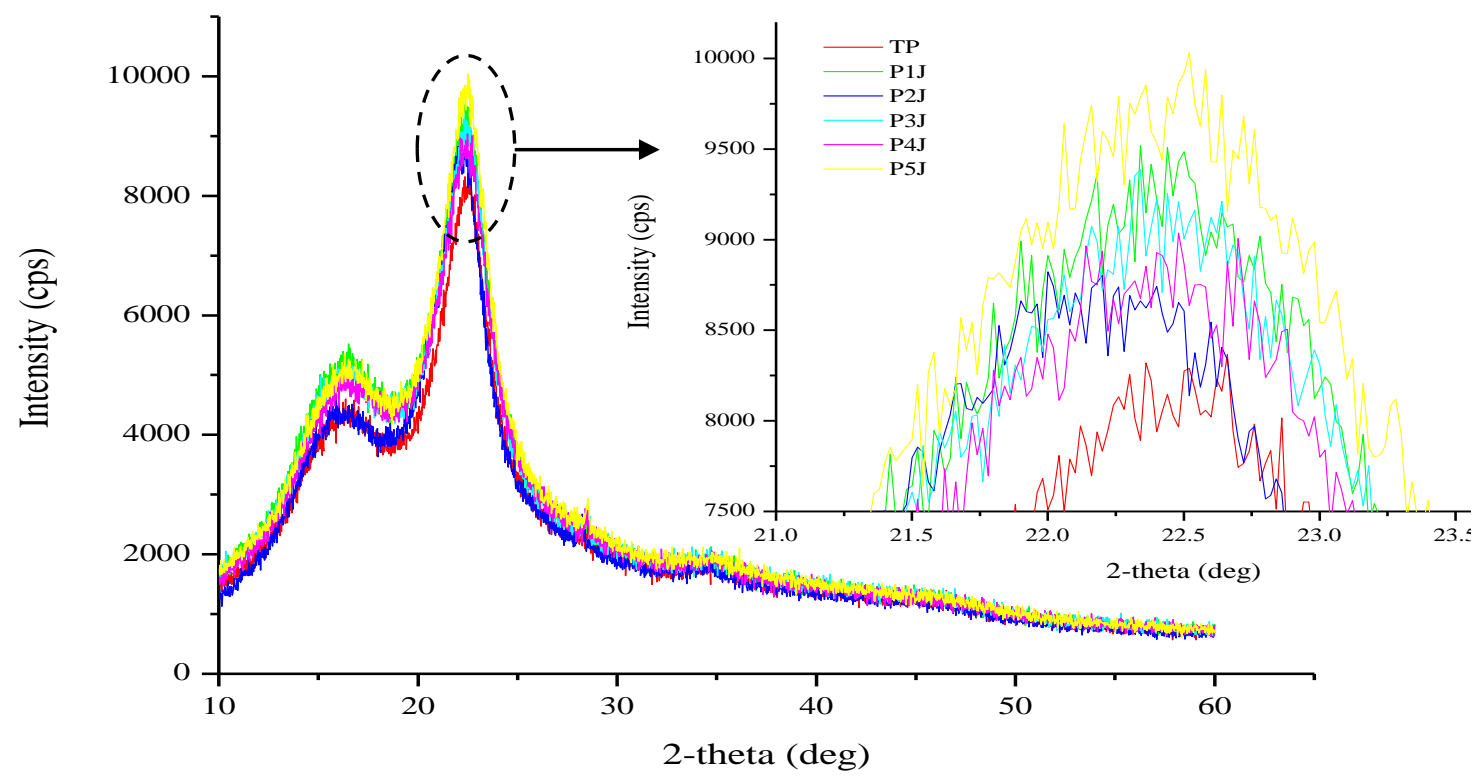

Figure 2. The result of SF for no treatment (TP), 1 hours immersion (P1J), 2 hours immersion (P2J), 3 hours immersion (P3J), 4 hours immersion (P4J), 5 hours immersion (P5J). 
It is evident from Table 2 that relative intensities of SF at $2 \theta$ scale were $4280\left(\mathrm{I}_{10}\right)$ and 8276.7 $\left(\mathrm{I}_{60}\right)$. The percentage crystallinity $(\% \mathrm{Cr})$ of SF has been found to be 65.9 . Whereas SF treated with liquid smoke for 1 hour showed relative intensities of $5203.3\left(\mathrm{I}_{10}\right)$ and $9486.7\left(\mathrm{I}_{60}\right)$. Relative intensities of SF treated with liquid smoke for 2 hours were $4336.7\left(\mathrm{I}_{10}\right)$ and 8690 ( $\left.\mathrm{I}_{60}\right)$. The percentage crystallinity of SF treated with 1 hours and 2 hours were 64.5 and 66.7, respectively. The relative intensities of SF treated with 3 hours were $4883.3\left(\mathrm{I}_{10}\right)$ and 9003.3 $\left(\mathrm{I}_{60}\right)$. The percentage crystallinity of SF was found to be 64.8. Whereas SF treated with liquid smoke for 4 hours showed relative intensities of 4846.7 ( $\left.\mathrm{I}_{10}\right)$ and 8913.3 ( $\left.\mathrm{I}_{60}\right)$. Relative intensities of SF treated with liquid smoke for 5 hours were $4946.7\left(\mathrm{I}_{10}\right)$ and 10033.3 ( $\left.\mathrm{I}_{60}\right)$. The percentage crystallinity of SF treated with 4 hours and 5 hours were 64.7 and 66.9 , respectively.

Table 3. The percentage of crystalline of SF specimen.

\begin{tabular}{cccc}
\hline Notation & $\begin{array}{c}\text { I10 } \\
(\mathbf{c p s})\end{array}$ & $\begin{array}{c}\text { I60 } \\
(\mathbf{c p s})\end{array}$ & $\begin{array}{c}\mathbf{C r} \\
(\boldsymbol{\%})\end{array}$ \\
\hline TP & 4280 & 8276.7 & 65.9 \\
P1J & 5203.3 & 9486.7 & 64.5 \\
P2J & 4336.7 & 8690 & 66.7 \\
P3J & 4883.3 & 9003.3 & 64.8 \\
P4J & 4846.7 & 8913.3 & 64.7 \\
P5J & 4946.7 & 10033.3 & 66.9 \\
\hline
\end{tabular}

\section{FTIR Structure Analyses}

The change of the compound was proved by FTIR (Shimadzu prestige-21 model 8400S). Figure 9 shows the difference of fiber compounds composition before and after treatments. Analysis using FTIR to find out the changes of the functional group of SF compound due to the treatment of liquid smoke in various timeframe. The graph of FTIR transmittance incorporation patterns as shown in the following Figure 3: 


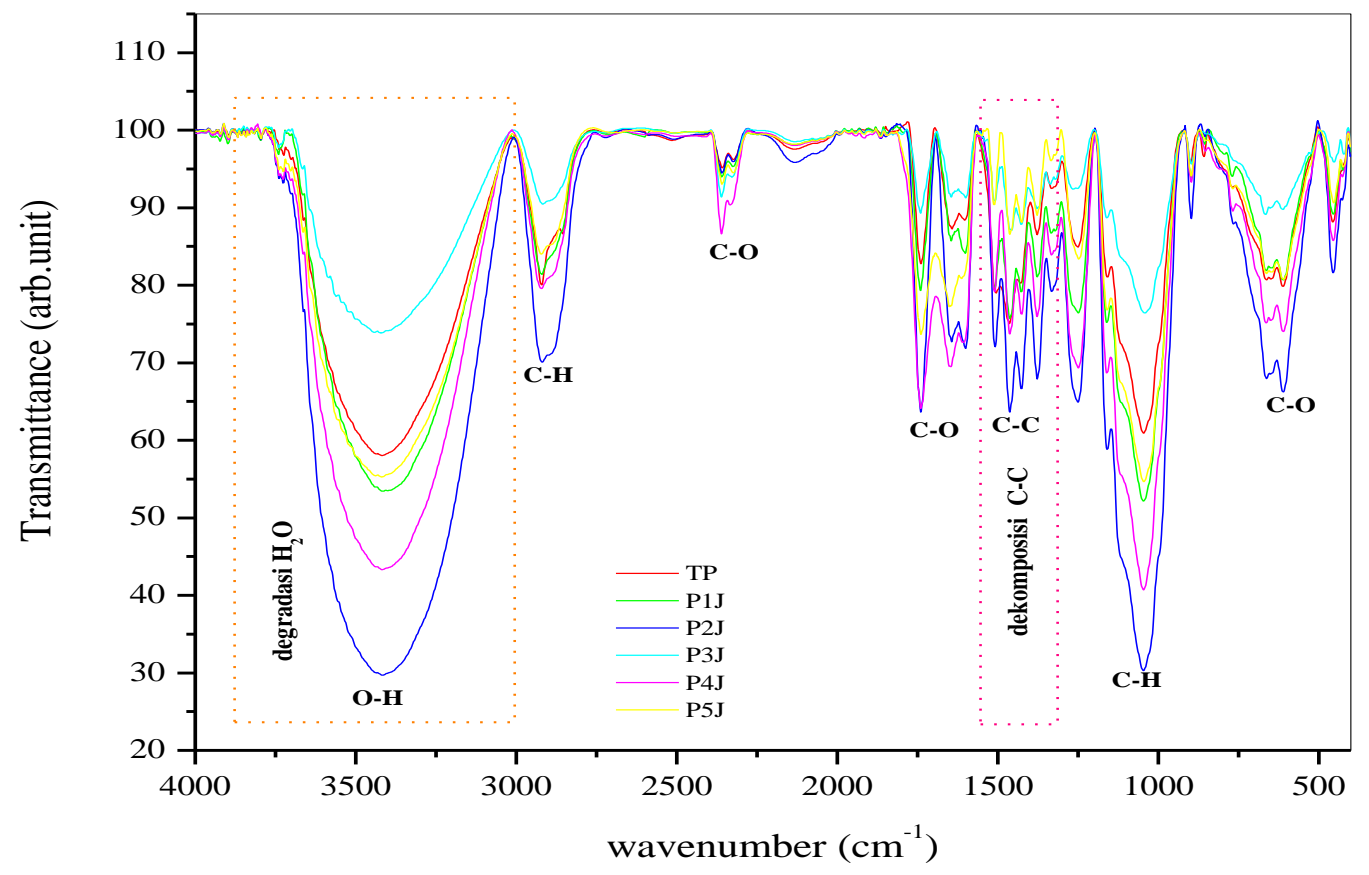

Figure 3. FTIR test results for non-treated (TP) and $1-5$ hours immersion (P1J-P5J) of SF.

Figure 3 shows the incorporation of the FTIR transmittance patterns of no treatment and with treatment of SF. Where the peak shape changes, explain that treatment with liquid smoke affects the wave crest, wherein the liquid smoke compound acetic acid can break the chain of fiber compounds, an acetic acid was able to break the chain of fiber compounds such as lignin and hemicelluloses [9].

The molecule of SF composed of $\mathrm{OH}$ groups with a range of $3000-4000 \mathrm{~cm}^{-1}$, the hydrogen bonding $(\mathrm{OH})$ group in the fiber undergoes changes after treatment. In the range of 2850-3000 $\mathrm{cm}^{-1}$ wave range associated with the $\mathrm{C}=\mathrm{H}$ bonds observed in the alkenes group. The peak of the $\mathrm{C}=\mathrm{O}$ group in the ketene is observed in the peak range $1715-1765 \mathrm{~cm}^{-1}$ and $\mathrm{C}=\mathrm{O}$ in the carbonyl in the peak range $2000-2500 \mathrm{~cm}^{-1}$. Peak cluster $\mathrm{C}=\mathrm{C}$ in the range 1450 $1650 \mathrm{~cm}^{-1}$.

The degradation process after 1-5 hours treatment process decreased the OH group in the range $3000-4000 \mathrm{~cm}^{-1}$ and the decomposition process of $\mathrm{C}=\mathrm{C}$ group also occurred in the range 1450-1650 $\mathrm{cm}^{-1}$. The change of the $\mathrm{OH}$ group on the degraded fiber becomes free released water so that the fiber surface becomes coarse, grooved, and porous where diameter of fiber decreased. Meanwhile, the decomposition of the $\mathrm{C}=\mathrm{C}$ group forms a tighter bond increasing the tensile strength of the fiber.

The chemical process of immersing the fibers in liquid smoke forms a liquid-fibersmoke compound. Thus, the formation of the compound will increase the composition of $\mathrm{C}$, $\mathrm{H}$, and $\mathrm{O}$ on the fiber compound. Liquid smoke of SF took place as per the following schemes: 


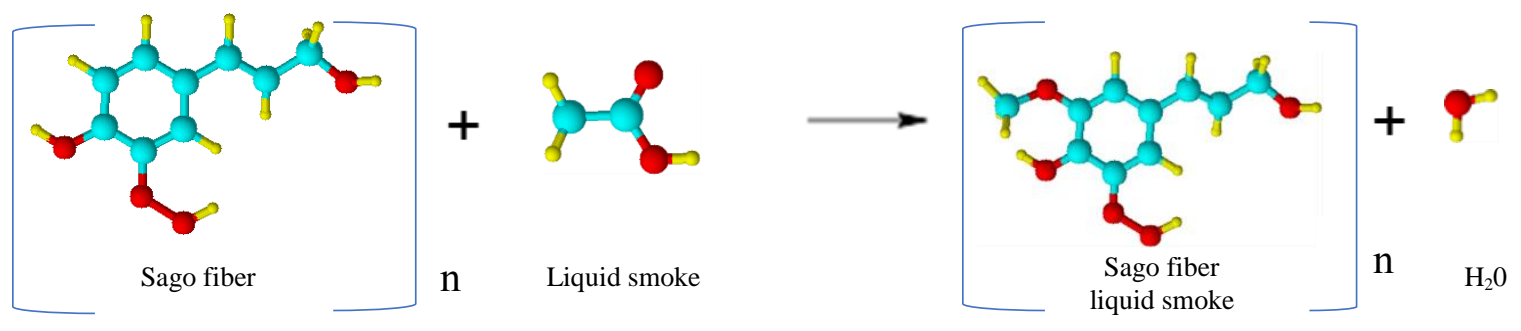

Figure 4. The process of SFand liquid smoke compounds formation.

$\mathrm{SF}$ and liquid smoke compounds are compounds containing $\mathrm{OH}$ radicals, the polarity of $\mathrm{OH}$ group in fiber and liquid smoke molecules can form a relatively strong hydrogen bridge between molecules in the liquid phase. During heating process with temperature $43^{\circ} \mathrm{C}$, degradation process occurred between element $\mathrm{O}$ and $\mathrm{H}$ as $\mathrm{H}_{2} \mathrm{O}$, while $\mathrm{C}$ element were decomposed and diameter of fiber becomes smaller, porous, grooved, and coarser on fiber surface. The degradation process on the fiber as sketched in the following figure:

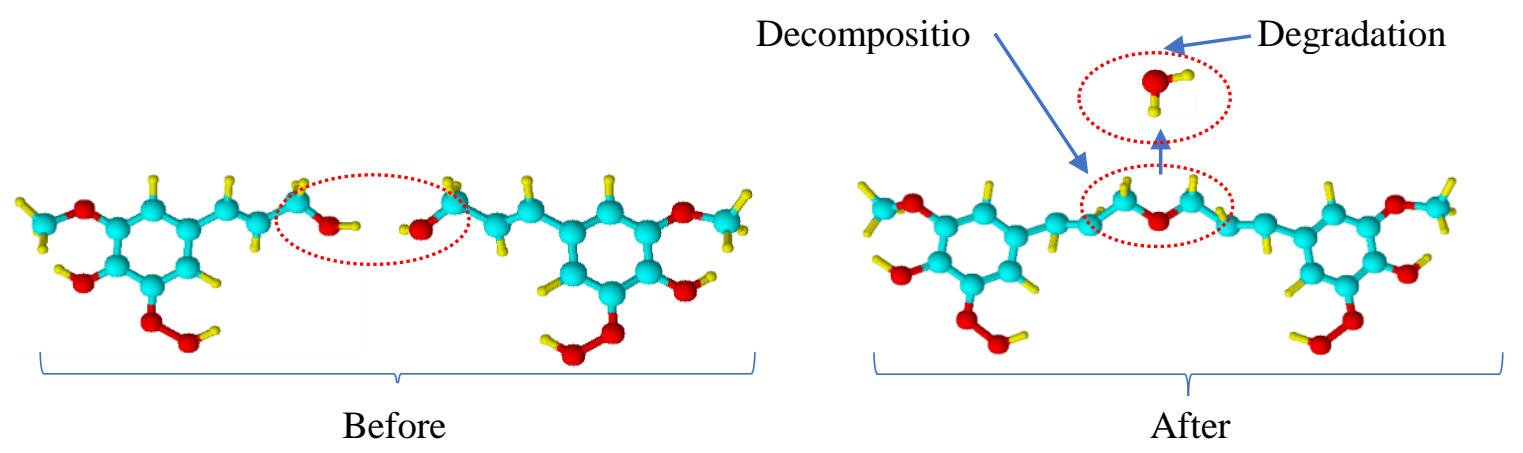

Figure 5. Degradation process of $\mathrm{H}, \mathrm{O}$ elements and decomposition of $\mathrm{C}$.

The degradation process forms the SF cross-sectional area to become smaller $\left(\mathrm{A}_{1}<\right.$ $\left.A_{0}\right)$. Here, $A_{0}$ is the initial cross-sectional area while $A_{1}$ is the cross-sectional area after heating, as shown in Figure 6.

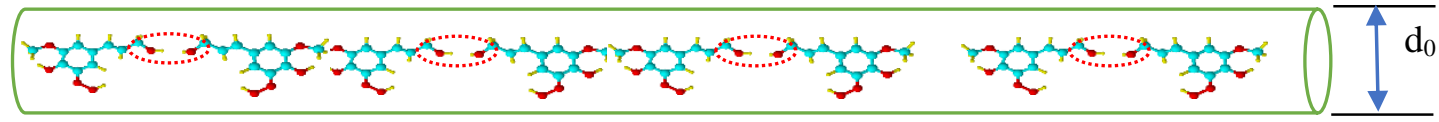

(a)

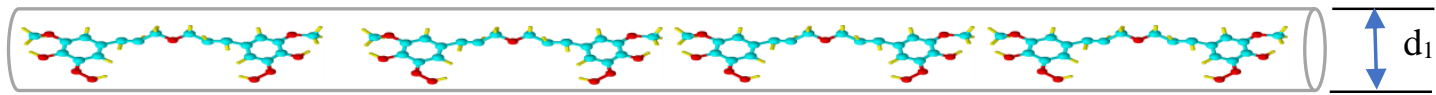

(b)

Figure 6. Changes in cross-sectional area of SF: (a) Fiber diameter before heating $\left(\mathrm{d}_{0}\right)$ and (b) Fiber diameter after heating $\left(\mathrm{d}_{1}\right)$. 
While decomposition of $\mathrm{C}$ element on SF compounds occurred, consequently the distances between $\mathrm{C}$ compounds become closer, produces stronger interconnection force so that the tensile strength of a single fiber increases as fiber surface becomes rough, porous, and grooved [4][3]. Decomposition can be caused by loss of moistures or due to cellulose and lignin degradations [22], as shown in Figure 7.

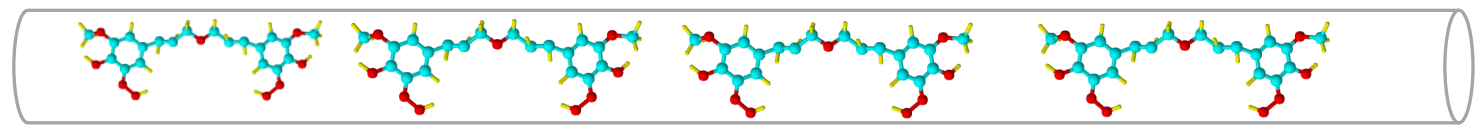

Figure 7. The form of fiber compound due to decomposition.

\section{Tensile Strength Analysis}

Tensile strength of natural fibers is important characteristic for bio composite applications, thus certain treatments are required to improve the characteristic. As one of natural fibers, SF samples were treated with liquid smoke and showed significant results on the increasing tensile strength of the SF.

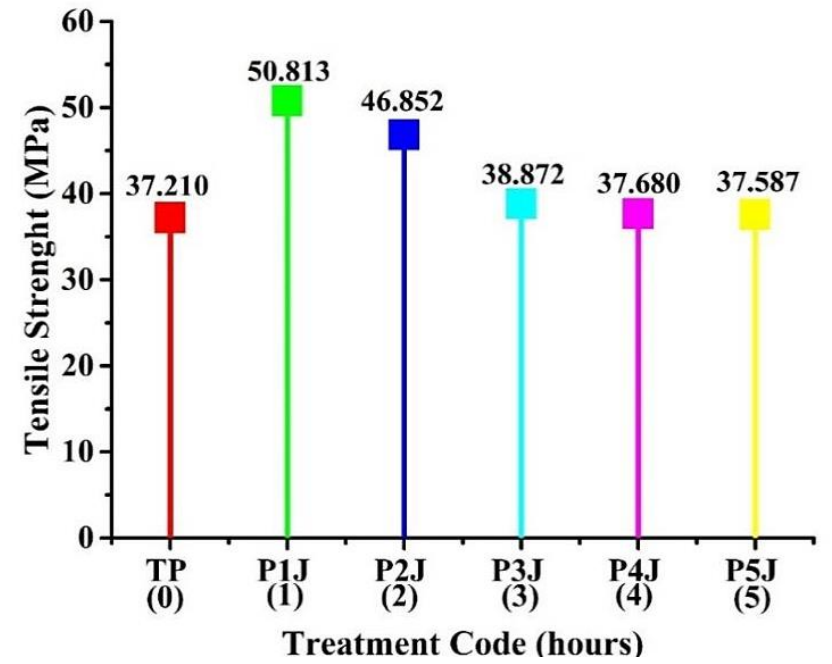

Figure 8. Tensile strengths of SF with no treatment (TP) and 1-5 hours immersion (P1J P5J).

As shown on Figure 8, in comparison to SF without treatment (TP) by tensile strength of 37.210 MPa, improvement of tensile strengths $(\Delta \sigma)$ were occurred to all treated SF, labeled as P1J, P2J, P3J, P4J, and P5J by 50.813, 46.852, 38.872, 37.680 and $37.587 \mathrm{MPa}$, respectively. The highest tensile strength among these treated SF was achieved by 1 hour immersion in liquid smoke with almost $40 \%$ increased strength, from 37.210 to $50.813 \mathrm{MPa}$. From this point, continuing the immersion to another 2 to 5 hours had degraded the SF tensile strengths, gradually down to only $37.587 \mathrm{MPa}$. The last treatment of 5 hours immersion (P5J) only managed to improve tensile strength of untreated SF by just $1 \%$ higher. After 1 hour treatment, the decreased trends of tensile strengths assume that duration of immersions should determine the level of SF deterioration along with weaker tensile strengths. Hence, 
this study recommends maximum 1 hour immersion in order to improve the SF tensile strength due to longer durations should alter the tensile strength in a negative state.

\section{CONCLUSIONS}

The effects of SF treatment in liquid smoke can be explained as follows:

1. The acetic acid in liquid smoke reacts with fiber in the immersion process to form fiber-liquid and $\mathrm{H}_{2} \mathrm{O}$ compounds. Furthermore, the heating process facilitates the degradation process of $\mathrm{H}_{2} \mathrm{O}$ content in fibers and makes $\mathrm{C}$ and $\mathrm{C}$ elements to close together to form strong chemical bonds so that the tensile strength increases and fiber morphology become rough, porous, and grooved.

2. The significant increase of tensile strength of $50.813 \mathrm{MPa}$ was achieved by 1-hour immersion in liquid smoke, so that may be considered as composite enforcement fiber alternative. However, longer than 1 hour treatment should make the fibers become dense and brittle due to degradation of $\mathrm{H}_{2} \mathrm{O}$ elements is too excessive.

3. Among other durations, dominant percentage of SF crystallization occurred after 4 and 5 hours, by 64.7 and $66.9 \%$, respectively.

\section{ACKNOWLEDGEMENTS}

This study is partly supported by Kemenristekdikti through the scheme of BUDI-DN LPDP Scholarship 2016 to 2020 in term of providing financial supports for this study.

\section{REFERENCES}

[1] Halim NA, Siregar JP, Mativanan D, Bachtiar D, Ghazali Z, Rejab MRM, Tezara C. The performance of mengkuang leaf fiber reinforced low density polyethylene composites. Journal of Mechanical Engineering and Sciences. 2018;12:3645-3655.

[2] Chafidz A, Rizal M, Faisal RM, Kaavessina M, Hartanto D, Alzahrani SM. Processing and properties of high density polyethylene/date palm fiber composite prepared by a laboratory mixxing extruder. Journal of Mechanical Engineering and Sciences. 2018;12:3771-3785.

[3] Arsyad M, Wardana ING, Pratikto, Irawan YS. The morphology of coconut fiber surface under chemical treatment. REVISTAMATERIA. 2015;20:169-177.

[4] Bondaris PM, Soenoko R, Irawan YS, Purnowidodo A. The effect of fumigation treatment towards Agave Cantala Roxb Fibre strength and morfology. Journal of Engineering Science and Technology. 2017;12:1399-1414.

[5] Mardin, Wardana ING, Pratikto, Suprapto W, Kamil K. Effect of sugar palm fiber surface on interfacial bonding with natural sago matrix. Advances in Material Science and Engineering. 2016; 2016:1-5.

[6] Renreng I, Soenoko R, Pratikto, Irawan YS. Effect of turmeric (curcuma) solution treatment toward the interfacial shear stress and wettabilty of a single fiber Akaa 
(corypha) on epoxy matrix. International Journal of Applied Engineering Research. 2015;10:973-4562.

[7] Kumaar AS, Senthilkumar A, Sornakumar T, Saravanakumar SS, Arthanariesewaran VP. Physicochemical properties of new cellulosic fiber extracted from Carica papaya bark. Journal of Natural Fibers, 2019;16:175-184.

[8] Senthamaraikannan P, Sanjay MR, Bhat KS, Padmaraj NH, Jawaid M. Characterization of natural cellulosic fiber from bark of Albizia amara. Journal of Natural Fibers. 2018; 1-8.

[9] Dufresne A, Amroune S, Bezazi A, Maache M, Scarpa F. Characterization of a novel natural cellulosic fiber from Juncus effusus L. Carbohydrate Polymers. 2017;171:163-172.

[10] Bondaris PM, Soenoko R, Irawan YS, Purnowidodo A. Structure crystallization of cellulose king pineapple leafs fiber (agave cantala roxb) due to smoke fumigation. ARPN Journal of Engineering and Applied Sciences. 2017;12:5721-5725.

[11] Sari NH, Wardana ING, Irawan YS, and Siswanto E. Characterization of the chemical, physical, and mechanical properties of $\mathrm{NaOH}$-treated natural cellulosic Fibers from Corn Husks. Journal of Natural Fibers. 2017;15:545-558

[12] Mardin, Wardana ING, Pratikto, Suprapto W, Kamil K. Sea water effects on surface morphology and interfacial bonding of sugar palm fiber to sago matrix. Key Engineering Materials. 2016;724:39-42.

[13] Manikandan A, Rajkumar R. Physicochemical and tensile properties of alkalinetreated new natural cellulosic gossypium arboreum fiber. International Journal of Polymer Analysis and Characterization. 2016;21:628-635.

[14] Mardin H, Wardhana ING, Pratikto, Suprapto W. Effects of sugar palm fiber immersed in sea water toward the palm fiber tensile strength as a composite strengthen. International Journal of Applied Engineering Research. 2015;10:1703717045.

[15] Bondaris PM, Soenoko R, Irawan YS, Purnowidodo A. The effect of fumigation toward the engagement ability of king pineapale leaf fibre (agave cantala roxb) with epoxy matrix, ARPN Journal of Engineering and Applied Sciences. 2016;11:85328537.

[16] Li X, Tabil LG, Panigrahi S. Chemical treatments of natural fiber for use in natural fiber-reinforced composites: A review. Journal of Polymer and the Environment. 2007; 15:25-33.

[17] Suryanto H, Marsyahyo E, Irawan YS, Soenoko R. Morphology, structure, and mechanical properties of natural cellulose fiber from mendong grass (Fimbristylis globulosa). Journal of Natural Fibers. 2014;11:333-351.

[18] Al-Mobarak T, Mina MF, Gafur MA, Ahmed AN, Dhar SA. Effect of chemical modifications on surface morphological, structural, mechanical, and thermal properties of sponge-gourd natural fiber. Fibers and Polymers. 2018;19:31-40.

[19] Zuraida I, Sukarno, Budijanto. Antibacterial activity of coconut shell liquid smoke (CS-LS) and its application on fish ball preservation. International Food Research journal. 2011;18:405-410.

[20] Lingbeck JM, Cordero P, O’Bryan CA, Johnson MG, Ricke SC, Crandall PG. Functionality of liquid smoke as an all-natural antimicrobial in food preservation. Meat Sci. 2014;97:197-206. 
[21] Soares JM, Dasilva PF, Puton BMS, Brustolin AP, Cansian RL, Dallago RM, Valduga E. Antimicrobial and antioxidant activity of liquid smoke and its potential application to bacon, Innovative Food Science and Emerging Technologies. 2016;38:189-197.

[22] Kalia S, Kaushik VK, Sharma RK. Effect of benzoylation and graft copolymerization on morphology, thermal stability, and crystallinity of sisal fibers. Journal of Natural Fibers. 2011;8:27-38. 